\title{
Evolution of clay fabric and water retention properties along hydromechanical stress paths
}

\author{
A.C. Dieudonne \\ ArGEnCo Department, University of Liege, Liege, Belgium \\ F.R.I.A., Fond de la Recherche Scientifique - FNRS, Brussels, Belgium \\ R. Charlier, S. Levasseur \\ ArGEnCo Department, University of Liege, Liege, Belgium \\ G. Della Vecchia \\ Department of Civil and Environmental Engineering, Politecnico di Milano, Milano, Italy \\ C. Jommi \\ Department of Geosciences and Engineering, TU Delft, Delft, The Netherlands
}

\begin{abstract}
The paper presents a water retention model for compacted clayey soils. The model is based on a description of the aggregated structure of the material and its evolution along generalized hydraulic and mechanical stress paths. The water retention properties of each structural level are distinguished and described separately using an expression of the type proposed by van Genuchten (1980). The water retention model is validated against experimental data on Boom Clay compacted at different dry densities. Its qualitative performance are highlighted along a complex hydromechanical path. The proposed formulation succeeds in tracking simultaneously the evolution of the fabric pattern and of the hydraulic state of compacted clays along generalized stress paths.
\end{abstract}

\section{INTRODUCTION}

Compacted clays are used in a wide range of geotechnical and geo-environmental applications. In civil engineering, compacted clayey soils are found in embankments and earth dams, whereas they are considered as engineered barriers for the disposal of domestic, industrial and hazardous waste. In these applications, the compacted material remains essentially unsaturated over its service life. The characterization of its water retention properties is thus fundamental to a comprehensive understanding and modelling of the coupled response of the material in terms of water flow and deformation processes.

Since many years, numerous studies have recognised the importance of the material structure on the engineered properties of compacted clayey soils (see Romero 2013 for a review). While compacted on the dry side of optimum, clayey soils exhibit a typical aggregated fabric. This fabric is not unique and the size of the aggregates appears to be sensitive to the compaction water content (Thom et al. 2007, Birle 2012), the chemical composition of the inter- stitial fluid (Musso et al. 2013) and the particular hydromechanical path followed during compaction (Delage 2010). In addition, the structure is not fixed but evolves along with mechanical, hydraulic or chemical loading (see for instance Romero et al. 1999, Cuisinier and Laloui 2004, Della Vecchia 2009, Monroy et al. 2010, Romero et al. 2011, Casini et al. 2012, Wang et al. 2013).

In the last years, increasing attention has been paid to the links between the water retention properties of a soil and its evolving pore size distribution (PSD). Durner (1994) modelled successfully the water retention behaviour of a sandy loam, distinguishing explicitly in the formulation the existence of two structural levels. The same approach was later used by Gitirana Jr. and Fredlund (2004) on a pelletized diatomaceous soil and on a residual, highly collapsible clay from Brasilia. Romero and Vaunat (2000) distinguished an intra-aggregate water region and inter-aggregate water region to model the retention behaviour of Boom Clay. However none of these Authors have considered explicitly the evolutionary 
character of the material structure along hydromechanical stress paths. Early attempts to include the evolution of the structure into a water retention model are due to Simms and Yanful (2002, 2004), Romero et al. (2011) and Della Vecchia et al. (2013).

In this paper, a water retention model for compacted clayey clays is proposed. The model takes into account the aggregated structure of the material as it is directly linked to its pore size density function through Laplace equation. The model is validated against experimental data on compacted Boom Clay. Finally the model capabilities are assessed along a complex hydromechanical stress path.

\section{THEORETICAL FORMULATION}

The water retention model is written as the superposition of two elementary curves, using the approach proposed by Othmer et al. (1991) and Durner (1994). Each elementary curve is used to describe the water retention properties of a structural level. In this paper, van Genuchten model (van Genuchten 1980) is adopted for the description of the retention behaviour of both microstructural and macrostructural levels. The water ratio $e_{w}$, defined as the volume of water over the volume of solids, is given by:

$$
\begin{aligned}
e_{w}(s)= & e_{m}\left[1+\left(\frac{s}{s_{0}^{(m)}}\right)^{n^{(m)}}\right]^{-m^{(m)}} \\
& +\left(e-e_{m}\right)\left[1+\left(\frac{s}{s_{0}^{(M)}}\right)^{n^{(M)}}\right]^{-m^{(M)}}
\end{aligned}
$$

where $s$ is the suction, $e$ and $e_{m}$ are the total and microstructural void ratios, $s_{0}^{(m)}$ and $s_{0}^{(M)}$ are measures of the microstructural and macrostructural air-entry pressures and $n^{(m)}, m^{(m)}, n^{(M)}$ and $m^{(M)}$ are model parameters.

The dependency of the microstructural void ratio $e_{m}$ on the water content has been highlighted by (Romero et al. 2011). In this paper, the following relationship is used:

$e_{m}=\beta_{0} e_{w}^{2}+\beta_{1} e_{w}+e_{m, 0}$

where $\beta_{0}$ and $\beta_{1}$ quantify the swelling tendency of the aggregates and $e_{m, 0}$ is the microstructural void ratio of the dry material. This equation is similar to the one proposed by Romero et al. (2011), except that it suggests a continuous evolution of the microstructural void ratio with water ratio.

Considering the Washburn equation (Washburn 1921), relating the suction $s$ to an equivalent pore diameter $x$, a theoretical pore size density (PSD) model

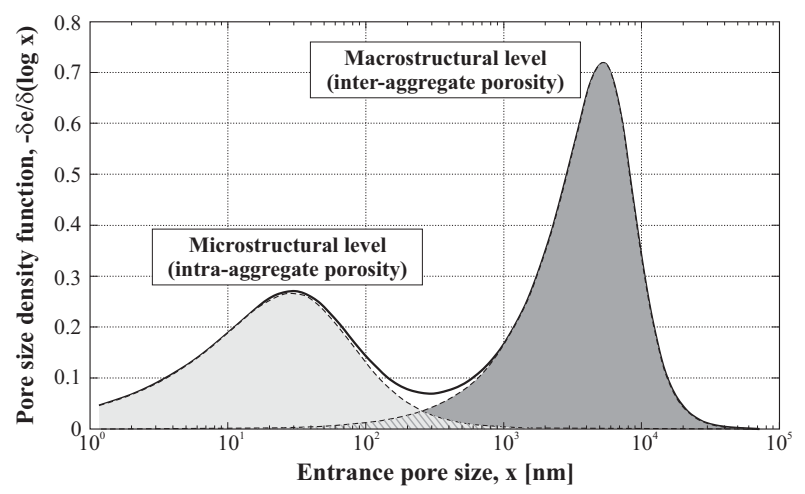

Figure 1: Theoretical pore size distribution derived from the proposed water retention model.

can be derived directly from equation (1):

$$
P S D \equiv \frac{\partial e_{w}}{\partial \log x}=-\frac{4 \sigma \cos \theta_{w}}{x \log \mathrm{e}} \frac{\partial e_{w}}{\partial s}
$$

where $\sigma=0.07275 \mathrm{~N} / \mathrm{m}$ is the air/water surface tension and $\theta_{w}=0^{\circ}$ is the water-solid contact angle.

Figure 1 presents the theoretical pore size distribution derived from the water retention model. The model parameters $s_{0}, n$ and $m$ can thus be interpreted with reference to the pore size density function. The value of $s_{0}$ is related to the position, on the x-axis, of the maximum values of the PSD function, while $n$ and $m$ are associated to the width and the shape of the pore size distribution.

Dieudonne et al. (2013) have highlighted the evolution of the microstructural and macrostructural parameters $s_{0}^{(m)}$ and $s_{0}^{(M)}$ along hydraulic and mechanical loading stress path. Experimental PSD data on compacted Boom Clay from Della Vecchia (2009) and on compacted London Clay from Monroy et al. (2010) were used to calibrate the model. According to experimental evidence, the parameters $s_{0}^{(m)}$ and $s_{0}^{(M)}$ are assumed to evolve exponentially respectively with the microstructural void ratio $e_{m}$ and with the ratio $\left(e-e_{m}\right) / e$, representing the ratio between the macrostructural and the total void ratios:

$$
\begin{aligned}
& s_{0}^{(m)}=\alpha_{1}^{(m)} \exp \left(-\alpha_{2}^{(m)} e_{m}\right) \\
& s_{0}^{(M)}=\alpha_{1}^{(M)} \exp \left(-\alpha_{2}^{(M)} \frac{e-e_{m}}{e}\right)
\end{aligned}
$$

where $\alpha_{1}$ and $\alpha_{2}$ are model parameters (Figure 2).

Equations (1) - (5) describe a state surface in the suction - void ratio - degree of saturation space. This surface is depicted in Figure 3 for Boom Clay, using the model parameters presented in Table 1. The dependency of the water retention curve on the void ratio is clearly highlighted.

\section{EXPERIMENTAL VALIDATION}

The proposed water retention model has been validated against experimental data on Compacted Boom 


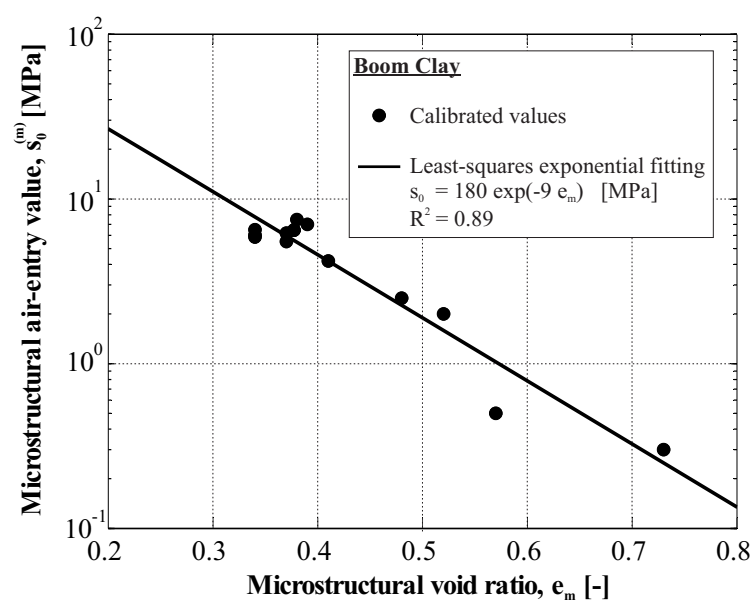

(a) Dependence of the microstructural air-entry pressure with the microstructural void ratio.

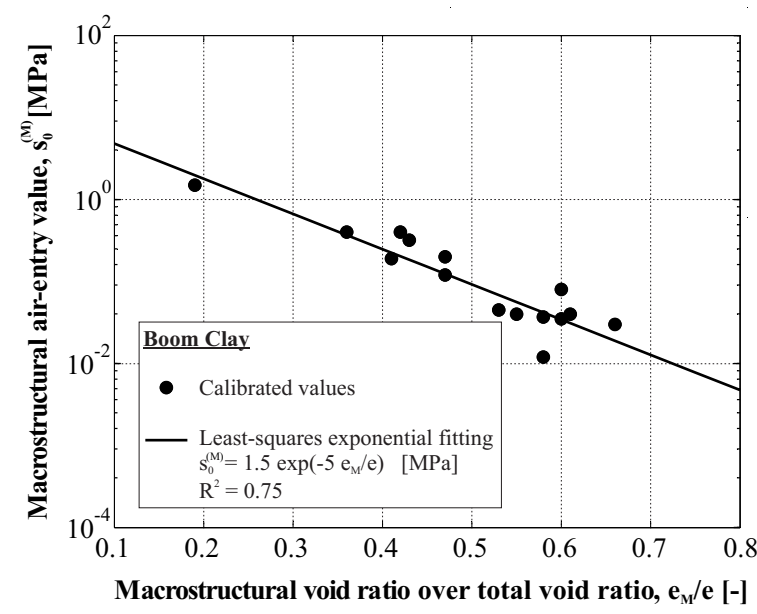

(b) Dependence of the macrostructural air-entry pressure with the ratio of the macrostructural void ratio over the total void ratio.

Figure 2: Variation of the model parameters along hydromechanical stress paths.

Clay from Romero et al. (2011). The model parameters were first determined by calibrating the pore size distribution model against experimental PSD curves from Della Vecchia (2009). In total, 18 experimental PSD curves were fitted with equation (3) in a systematic way in order to highlight the influence of various hydromechanical stress paths, such as wetting, drying and loading. Details concerning the calibration process have been presented in Dieudonne et al. (2013).

In accordance with the calibration of the pore size distribution model, the parameters $n^{(m)}, m^{(m)}, n^{(M)}$ and $m^{(M)}$ are set constant. All parameter values are presented in Table 1. Regarding the evolution of the microstructural void ratio with the water content, the following parameters are used: $\beta_{0}=0.2, \beta_{1}=0.05$ and $e_{m, 0}=0.33$.

The performance of the model is presented in Figure 4. It can be observed that the model predictions compare favourably with the experimental data on Boom clay compacted at different void ratios $(e=$ 0.65 and $e=0.93$ ). The model succeeds in tracking the increase of air entry pressure with decreasing void ratio. Moreover, for high suction values, the model tends to reach a unique relationship between water ratio and suction, regardless the current value of void ratio. In this domain, the water retention is indeed dominated by the behaviour of the microstructure. On

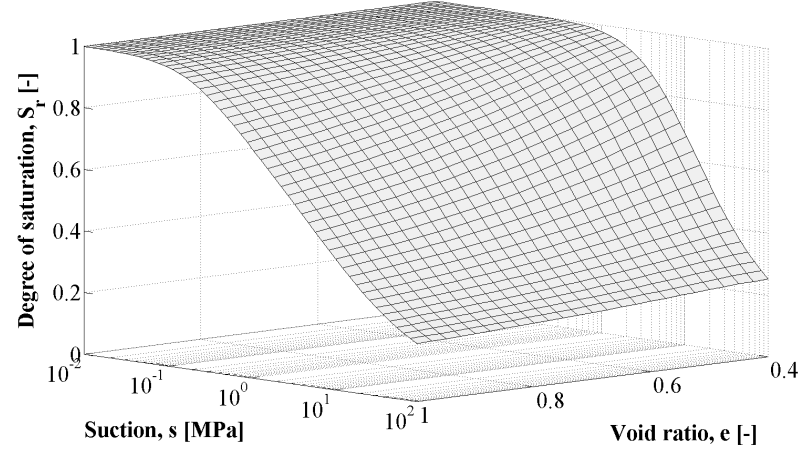

Figure 3: Predicted state surface in the $\left(s-e-S_{r}\right)$ space.

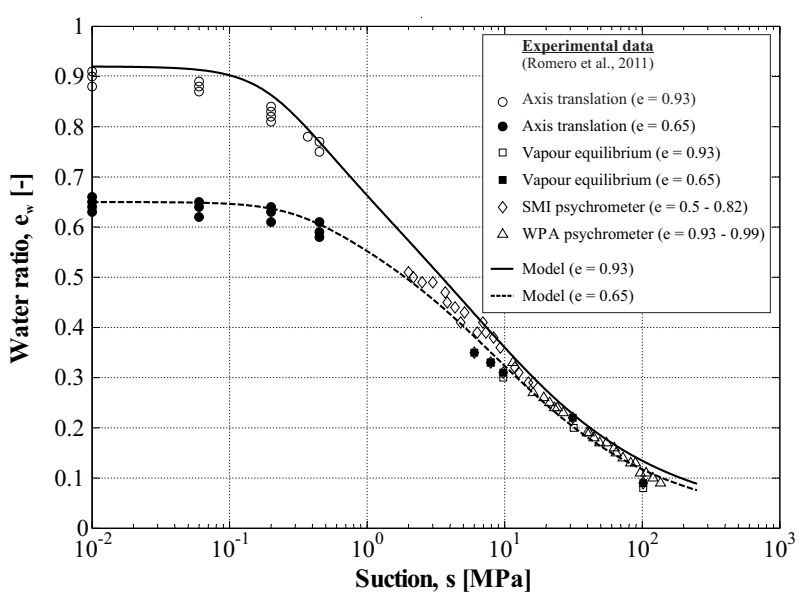

Figure 4: Comparison between experimental main drying paths for compacted Boom Clay (Romero et al. 2011) and model predictions at different void ratios.

the contrary, for low values of suction, the water retention curve is sensitive to mechanical actions. Being calibrated on a huge number of hydromechanical paths, the model can be fruitfully used to predict the hydraulic response of the material along different hydromechanical paths.

\section{ILLUSTRATIVE EXAMPLE}

The qualitative response of the water retention model is evaluated along a complex loading wetting unloading path. The mechanical behaviour of the material is modelled using the Barcelona Basic Model (Alonso et al. 1990) so that the total volumetric strain includes two distinct contributions: a first contribution related

Table 1: Parameters of the water retention model for Boom Clay.

\begin{tabular}{llll}
\hline \multicolumn{2}{c}{ Microstructural parameters } & \multicolumn{2}{c}{ Macrostructural parameters } \\
\hline$n^{(m)}$ & 1.65 & $n^{(M)}$ & 2.0 \\
$m^{(m)}$ & 0.35 & $m^{(M)}$ & 0.16 \\
$\alpha_{1}^{(m)}$ & $180 \mathrm{MPa}$ & $\alpha_{1}^{(M)}$ & $1.5 \mathrm{MPa}$ \\
$\alpha_{2}^{(m)}$ & 9.0 & $\alpha_{2}^{(M)}$ & 5.0 \\
\hline
\end{tabular}


to changes in the mean net stress pressure, and a second one associated to changes in suction.

The parameters of Boom Clay have been used in the simulations. An initial void ratio of 0.97 and an initial suction of $3 \mathrm{MPa}$ are considered, leading to an initial degree of saturation equal to 0.55. An aggregated structure is associated to this initial state of the material. It is depicted in Figure 5.

During a first stage (A), the material is loaded under oedometer conditions and constant water content up to a vertical net stress of $2.5 \mathrm{MPa}$. During loading, the material experiences a decrease in void ratio (Figure $6 \mathrm{~b}$ ). Figure 5 presents the evolution of the pore size distribution of the material and shows that loading affects mainly the macrostructural pore volume while maintaining almost constant the volume of micropores. In addition, the decrease of the porous space is associated with an increase in the degree of saturation which is highlighted in Figure 6a. We observe that the reduction in void ratio causes a shifting of the water retention curve towards higher values of suction for a given degree of saturation.

During a second loading stage, the material is saturated under constant vertical stress (B). The decrease in suction causes the material to swell, as shown in Figure $6 \mathrm{~b}$. The saturation process induces an increase in the microstructural void ratio. Being under a relatively high constant vertical stress, it is also associated with a decrease in the macropores diameter (Figure 5). Consequently, the material structure changes from an aggregated double structure to a monomodal pore size distribution.

Finally, the material is unloaded under constant water content $(\mathrm{C})$. The unloading process leads to swelling of the material which affects mainly the macrostructural voids.

\section{CONCLUSIONS}

The paper presents a water retention model for compacted clayey soils, accounting for the evolution of their aggregated structure along generalized hydromechanical stress paths. Microstructural and macrostructural water retention mechanisms are distinguished and described separately using an expres-

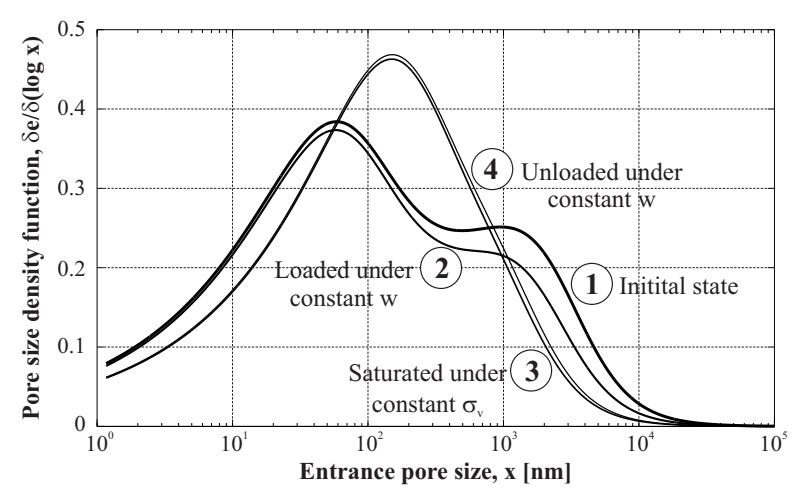

Figure 5: Evolution of the pore size distribution during sion of the type proposed by van Genuchten (1980). Using Washburn equation, a pore size density model is derived. Selected experimental data of pore size distribution on compacted clays were analysed and reinterpreted in the eyes of the proposed formulation in order to calibrate the model. The water retention model is then validated against experimental data on the same materials compacted at different dry densities. The performances of the model are then highlighted along a complex hydromechanical stress path along which the evolutions of the structure and of the water retention properties are analysed.

The proposed model captures important features of the retention behaviour of compacted clayey soils, such as the increase in microstructural porous volume with increasing water content, the increase in airentry pressure for decreasing macrostructural voids and the existence, in the high suction range, of an intra-aggregate water region which is almost not sensitive to the total void ratio.

\section{ACKNOWLEDGEMENTS}

The authors acknowledge the Belgian FRS-FNRS for its financial support during the stay of the first Author at the Politecnico di Milano.

\section{REFERENCES}

Alonso, E., A. Gens, \& A. Josa (1990). A constitutive model for partially saturated soils. Geotechnique 40, $405-430$.

Birle, E. (2012). Effect of initial water content and dry density on the pore structure and the soil-water retention curve of compacted clay. In C. Mancuso, C. Jommi, and F. D'Onza (Eds.), Unsaturated Soils: Research and Applications, pp. 145-152.

Casini, F., J. Vaunat, E. Romero, \& A. Desider (2012). Consequences on water retention properties of double-porosity features in a compacted silt. Acta Geotechnica 7, 139-150.

Cuisinier, O. \& L. Laloui (2004). Fabric evolution during hydromechanical loading of a compacted silt. Int. J. Num. Anal. Meth. Geomech. 28, 483-499.

Delage, P. (2010). A microstructure approach to the sensitivity and compressibility of some eastern canada sensitive clays. Geotechnique 60, 353-368.

Della Vecchia, G. (2009). Coupled hydro-mechanical behaviour of compacted clayey soils. Ph. D. thesis, Politecnico di Milano.

Della Vecchia, G., C. Jommi, \& E. Romero (2013). A fully coupled elastic-plastic hydromechanical model for compacted soils accounting for clay activity. Int. J. Num. Anal. Meth. Geomech. 37, 503-535.

Dieudonne, A., S. Levasseur, R. Charlier, G. Della Vecchia, \& C. Jommi (2013). A water retention model for compacted clayey soils. In S. Pietruszczack and G. Pande (Eds.), Computational Geomechanics, pp. 23-31.

Durner, W. (1994). Hydraulic conductivity estimation for soils with heterogeneous pore structure. Water Resources Research 30, 211-223.

Gitirana Jr., G. \& D. Fredlund (2004). Soil-water characteristic curve equation with independent properties. J. of Geotech. and Geoenv. Engng., ASCE 130, 209-212.

Monroy, R., L. Zdravkovic, \& A. Ridley (2010). Evolution of microstructure in compacted London clay during wetting and loading. Geotechnique 60, 105-119. 


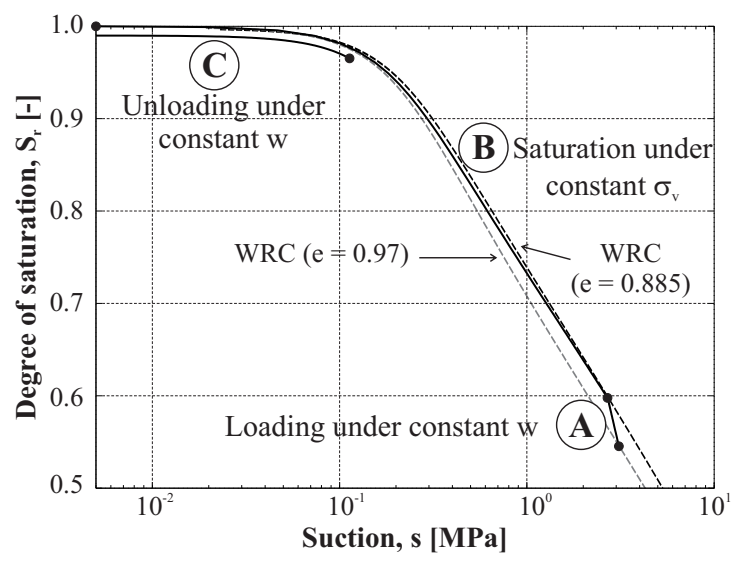

(a) Stress path in the $\left(s, S_{r}\right)$ plane

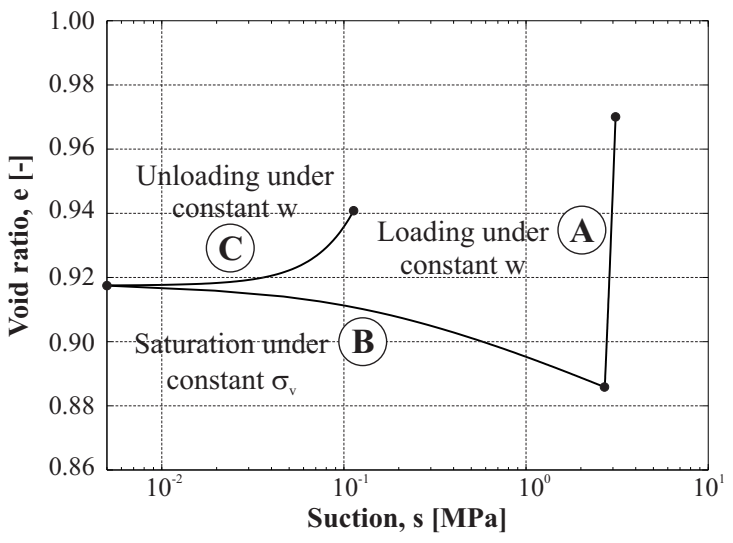

(b) Stress path in the $(s, e)$ plane

Figure 6: Evolution of the degree of saturation and the void ratio during a loading - saturation - unloading stress path performed under oedometer conditions.

Musso, G., E. Romero, \& G. Della Vecchia (2013). Doublestructure effects on the chemo-hydro-mechanical behaviour of a compacted active clay. Geotechnique 63, 206-220.

Othmer, H., B. Diekkruger, \& M. Kutilek (1991). Bimodal porosity and unsaturated hydraulic conductivity. Soil Sci. 152, 139-150.

Romero, E. (2013). A microstructural insight into compacted clayey soils and their hydraulic properties. Engineering $G e$ ology 165, 3-19.

Romero, E., G. Della Vecchia, \& C. Jommi (2011). An insight into the water retention properties of compacted clayey soils. Geotechnique 61, 313-328.

Romero, E., A. Gens, \& A. Lloret (1999). Water permeability, water retention and microstructure of unsaturated compacted boom clay. Engineering Geology 54, 117-127.

Romero, E. \& J. Vaunat (2000). Retention curves for deformable clays. In C. Tarantino, A. \& Mancuso (Ed.), Experimental Evidence and Theoretical Approaches in Unsaturated Soils, Balkema, Rotterdam, pp. 91-106.

Simms, P. \& E. Yanful (2002). Predicting soil-water characteristic curves of compacted plastic soils from measured pore-size distributions. Geotechnique 52, 269-278.

Simms, P. \& E. Yanful (2004). Estimation of soil-water characteristic curve of clayey till using measured pore-size distribution. J. Environ. Engng. 130, 847-854.

Thom, R., R. Sivakumar, V. Sivakumar, E. Murray, \& P. Mackinnon (2007). Pore size distribution of unsaturated compacted kaolin: the initial states and final states following saturation. Geotechnique 57, 469-474.

van Genuchten, M. (1980). A closed-form equation for predicting the hydraulic conductivity of unsaturated soils. Soil Sci. Soc. Am. 44, 892-898.

Wang, Q., Y. Cui, A. Tang, J. Barnichon, S. Saba, \& W. Ye (2013). Hydraulic conductivity and microstructure changes of compacted bentonite/sand mixture during hydration. Engineering Geology 164, 67-76.

Washburn, E. (1921). A method of determining the distribution of pore sizes in a porous material. Proc. Nat. Acad. Sci. 7 , 115 . 